\title{
Importance of Emotional Competence in Designing an Antidrug Education Curriculum for Junior Secondary School Students in Hong Kong
}

\author{
Ben M. F. Law ${ }^{1}$ and Tak Yan Lee ${ }^{2}$ \\ ${ }^{1}$ Department of Social Work and Social Administration, The University of \\ Hong Kong, Hong Kong \\ ${ }^{2}$ Department of Applied Social Studies, City University of Hong Kong, Hong Kong \\ Received 28 December 2010; Revised 15 February 2011; Accepted 16 August 2011 \\ Academic Editor: Joav Merrick
}

Adolescent substance abuse is a serious problem in Hong Kong. Antidrug education campaigns should aim at enhancing students' understanding of the effects of illegal drugs to themselves. Moreover, life skill training is important in helping adolescents face life's challenges without attempting to do drugs. A major component of life skill training is the promotion of emotional competence. The present study outlines the importance of emotional competence and adolescent development. For an antidrug education campaign to be effective, adolescents should be able to identify their emotions and understand their own emotion regulation mechanism. Likewise, they should be made aware of the consequences of their emotions and emotion-driven behaviors. Finally, the use of an inspirational story with a strong message against substance abuse to trigger emotions is recommended for designing an antidrug education curriculum. All these components are integrated in the newly developed curriculum of the P.A.T.H.S. Project in Hong Kong.

KEYWORDS: emotional competence, substance abuse, Hong Kong, Project P.A.T.H.S. 


\section{INTRODUCTION}

Adolescent substance abuse is a serious problem in Hong Kong. From 2006 to 2009, the percentage of drug abusers under the age of 21 among all reported cases has increased from 19\% to 24\% [1]. Many factors contribute to the problem [2], and the ecological model is a widely adopted approach to understand this problem [3]. On the individual level, curiosity, lack of psychosocial competencies, and coping skills, as well as feelings of emptiness, hopelessness, and lack of purpose, are the factors related to adolescent drug abuse. On the interpersonal level, undesirable peer influence is the most significant factor. On the school level, underachievement, undesirable after-school activities, and nonengagement are the critical factors. On the family level, marital disruption, cross-border working parents or marriages, and loose parental supervision are some of the possible factors. The factors on the societal level include the growing culture of addiction, easy access to drugs, and growing pessimistic values about upward social mobility. All these factors interact with each other and contribute to the prevalence of adolescent's substance abuse in Hong Kong.

The Hong Kong Special Administrative Region (HKSAR) Government is well aware of the youth drug problems. In his 2007 Policy Address, the Chief Executive of the Government proposed the formation of a high-level interdepartmental task force to address the problem [4]. In 2008 [5], the Chief Executive set out directions to tackle the problem and used the following paragraph in the Policy Address for this issue:

"Over the past year, the Task Force led by the Secretary for Justice has been working in full swing to map out strategies to combat the youth drug abuse problem. The Task Force has worked closely with anticrime and antidrug networks, solicited views from stakeholders, and enhanced collaboration among government departments, NGOs, and the community for the antidrug cause. A series of short- to medium-term measures, which are being implemented, cover preventive education and publicity, treatment and rehabilitation, law enforcement, and research. A two-year territory-wide antidrug campaign and the "Path Builders" initiative have been launched to foster a drug-free youth culture and to mobilise the whole community to provide assistance to our young people at different levels and through innovative ways. The Task Force will shortly publish a report on holistic and sustainable policies and measures for the long term." (Paragraph 79).

School drug testings have been initiated based on the abovementioned policy [6]. In 2010, the Chief Executive planned to enhance the manpower support for social work service in secondary schools so that the drug problems can be tackled [7]. There are three tiers of antidrug education in Hong Kong [8]. The first tier is focused on students in general, the aims of which are to enhance their knowledge towards the consequence of drug abuse and increase their ability to resist the temptation of taking drugs. Included in the first tier are school-based programs and activities provided by nongovernmental organizations (NGOs). The second tier is aimed at high-risk students, including those who have taken drugs but are not yet dependent on them. Community experts are mobilized to provide counseling so that these high-risk students would be drugfree. The third tier is concerned with students who are already drug dependent. The focus of the treatment is guiding them to undergo rehabilitation so that they can grow in a safe environment. All secondary schools have to provide Tier-One antidrug education to adolescent students. Owing to the active involvement of the Education Bureau and the increase in school social work manpower, secondary schools are considered as the most important sites for the commencement of antidrug education instead of the traditional community resources, such as police, NGOs, and medical organizations.

Although we adopted an ecological perspective to understand adolescent substance abuse, the targets of Tier-One antidrug education are the students in general. Shek [2] emphasizes that the programs should not scare adolescents and should not blame them for their weaknesses. Moreover, the programs should not aim solely at reduction strategies, that is, how to not take drugs, but should also strengthen students' coping strategies in life. In Australia, Meyer and Cahill [9] also suggest the following twelve principles for antidrug education in schools. 
Principle 1. Base drug education on sound theory and current research as well as use evaluation to inform decisions.

Principle 2. Embed drug education within a comprehensive, whole-school approach to promote health and wellbeing.

Principle 3. Establish drug education outcomes that are appropriate to the school context and contribute to the overall goal of minimizing drug-related harm.

Principle 4. Promote a safe, supportive, and inclusive school environment as part of efforts seeking to prevent or reduce drug-related harm.

Principle 5. Promote collaborative relationships between students, staff, families, and the broader community in the planning and implementation of school drug education.

Principle 6. Provide culturally appropriate, targeted, and responsive drug education that addresses local needs, values, and priorities.

Principle 7. Acknowledge that a range of risk and protective factors impact on health and education outcomes and influence choices about drug use.

Principle 8. Use consistent policy and practice to inform and manage responses to drug-related incidents and risks.

Principle 9. Locate programs within a curriculum framework, thus providing timely, developmentally appropriate, and ongoing drug education.

Principle 10. Ensure teachers are resourced and supported in their central role in delivering drug education programs.

Principle 11. Use student-centered, interactive strategies to develop students' knowledge, skills, attitudes, and values.

Principle 12. Provide accurate information and meaningful learning activities that dispel myths about drug use and focus on real-life contexts and challenges.

These principles comprise the core elements in establishing an antidrug school policy and school curriculum. However, importing and applying these principles from Australia to Hong Kong is difficult. First, despite various reforms [10], the Hong Kong education system still emphasizes academic scores and high grades; antidrug education is not the main agenda for school development. Antidrug education within whole-school approach may be a motto more than a wholehearted action (Principles 2, 3, and 4). Second, teachers in Hong Kong [11] are already stressed out with their own teaching workload. Consequently, ensuring that teachers are willing to equip additional antidrug resources is difficult. In addition, schools are not fully informed about the timely information on drug-related incidents and risks at their schools (Principles $1,6,8,9$, and 10). Third, both teachers and parents are averse to antidrug education because they think that it actually encourages drug experimentation; their thinking is that the students do not need such education because there is "no need" for it (Principle 5). Among these, only Principles 11 and 12 can be implemented more effectively. Students should be trained to combat drug abuse in a proactive manner. Two themes emerge for the consideration of antidrug education. First, students have the right to understand how the drugs affect themselves so that they can make wiser choices. Second, life skill training is more important than the reduction strategy. Students should be well equipped with coping and management skills that enable them to meet life's challenges, including drug abuse. 
Under this context, a school can develop its own antidrug curriculum by utilizing the resources from the Narcotics Division [12]. They can adopt established program packages, such as the Adolescent Health Programme from the Department of Health [13] and the Enhanced Smart Teen Project from the Education Bureau [14].

A new curriculum in a positive youth development program (Project Positive Adolescent Training through Holistic Social Programmes or P.A.T.H.S.) has been developed to address adolescent's substanceabuse issues, in which schools can be adopted as antidrug education centers. In the present paper, the connection of emotional competence and antidrug education is highlighted. Moreover, excerpts from the new P.A.T.H.S. curriculum are used in order to illustrate how antidrug education campaigns are conducted with theoretical support and empirical evidence.

\section{POSITIVE YOUTH DEVELOPMENT AND PROJECT P.A.T.H.S.}

Positive youth development is one of the research areas in the latest phase of the scientific study of adolescent development [15]. The underlying principle of positive youth development is that an adolescent can handle life challenges more successfully through the development and strengthening of identified intrapersonal and interpersonal qualities. In Hong Kong, the Hong Kong Jockey Club Charities Trust has launched a four-year project called "P.A.T.H.S. to Adulthood: A Jockey Club Youth Enhancement Scheme," since the start of the school year 2005/2006 in collaboration with the research team of five universities, the Social Welfare Department, and the Education Bureau. Since its inception, more than 200 secondary schools have joined this project, and almost 145,000 students have benefited from it. The project developed many school-based lessons so that students can develop 15 qualities [16], including bonding, social competence, emotional competence, cognitive competence, behavioral competence, moral competence, self-efficacy, prosocial norms, resilience, self-determination, spirituality, beliefs in future, clear and positive identity, prosocial involvement, and recognition for positive behavior.

An extension phase of the Project P.A.T.H.S. has been initiated in 2009, which is aimed at addressing five adolescent issues: substance abuse, sex issue, internet addiction, bullying, and money/success [17]. The goal of the extension phase is not to reduce adolescent developmental problems, but to promote psychosocial competencies so that adolescents can address the above-mentioned adolescent issues themselves. The program content itself is not a problem-based psychoeducational program; hence, knowledge and information transmission is not the main goal. Instead, the five adolescent issues are used as illustrations or factors so that a particular positive youth construct can be strengthened.

\section{EMOTIONAL COMPETENCE AND ADOLESCENT DEVELOPMENT}

Emotional competence includes “The awareness of one's emotions, the ability to understand others' emotions, the ability to use the vocabulary of emotion, the capacity for empathy, the ability to differentiate internal, subjective emotional experience from external emotional expression, the capacity to control emotional distress, an awareness of emotional messages within relationships, and the capacity for emotional management" [17].

An adolescent's emotional life is likely to influence areas such as school achievement and motivation $[18,19]$. Competence refers to proactive adaptation or coping. Coping [20] is defined as "Efforts...to manage environmental and internal demands and conflicts which tax or exceed a person's resources" (page 288). According to the coping model proposed by Lazarus and Folkman [21], different persons experience different forms of stresses in different events. Appraisals of the stress lead to various coping strategies. Various coping strategies refer to emotional, cognitive, and behavioral efforts that allow an individual to tolerate, escape, or minimize the effects of stresses so that situations can be improved, accepted, or avoided.

Emotional competence is, therefore, the acquisition and regulation of emotion so that a perceived stressful situation can be handled more effectively. A person should perceive, use, understand, and manage 
emotions properly [22]. He/she should be able to regulate his/her emotions and emotionally driven thinking and behavior. A person who is unable to regulate the intensity and duration of his/her internal emotional responses is more susceptible to undesirable social interaction [23] and less resilient to stressful events [24]. Emotional competence is one core component of resilience during adolescence [25, 26].

Before the age of one and a half years, babies and toddlers experience various primary emotions, such as surprise, interest, joy, anger, fear, and disgust [27]. By the age of three, toddlers start to develop their theories of mind, after which self-awareness emerges [28]. They acquire self-awareness through the acquisition and retention of societal standards, rules, and goals. Children start to have self-conscious emotions, such as embarrassment, envy, empathy, pride, shame, and guilt [19,23]. An emotion is also influenced by the children's temperament. When children reach the age of 6 to 12, parenting styles and attachment also influence their emotions [29].

Adolescents' emotion is influenced by their cognitive thinking, which can be immature [30]. They can be idealistic and hypocritical to other people. They can be argumentative to show off their reasoning abilities. However, they are indecisive and can be easily influenced by their external environment. They are self-conscious to the extent that they want to present their "best" to other people. They think that they are special and invulnerable, for example, "Other people will be addicted to drugs but not me." Their emotions are erratic, and their problems are especially prominent during junior secondary school.

Postulating the underlying reasons for adolescents' substance abuse is not difficult if we adopt Elkind's framework. In that framework, cognitive processes and emotional responses are interconnected. Adolescents hold more negative opinions to other people and the world. During adolescence, boys' life pursuits tend to be achievement-oriented, whereas girls' pursuits tend to be relationship-oriented [31]. If they do not get what they want, they feel nihilistic towards their own lives. When their emotions are erratic, they may use many means as outlets, such as internet addiction, sexual release, self-mutilation, and drug abuse. Given that many adolescents feel invulnerable, they do not know that they can be addicted to drugs more easily than they think.

The adoption of the developmental perspective in understanding emotional competence includes the consideration of cognitive process and physical growth of adolescents.

\section{COMPONENTS OF EMOTIONAL COMPETENCE IN ANTIDRUG EDUCATION}

Emotional competence is closely related to antidrug education. It is one of the life skills needed by adolescents in facing external challenges. Once their emotional competence is enhanced, they become less susceptible to substance abuse. When we adopt positive youth development in understanding adolescent's emotional competence, they know more than previously assumed [32]. Through constructive activities, some unnoticed personal qualities are revealed and elaborated.

Many ways to promote emotional competence in school-based curriculum, such as psychoeducational coping model and programs cultivating positive emotions, are available. The newly developed antidrug education for the P.A.T.H.S. curriculum ut ilizes three distinctive strategies in delivering the messages to adolescents.

\subsection{Identifying the Emotion}

A person normally does not clearly understand his/her emotion and emotion regulation mechanism. Talking about emotions is effective in helping adolescents to understand their own emotion and emotion regulation mechanism [23]. Instructors' reactions and correct display of emotion to adolescents' disclosure are critical. When we know our emotion mechanism and our preferential emotion-driven behavior, we can manage ourselves well before the next emotionally charged event occurs. Thus, our out-of-control behaviors are not likely to happen [33].

In the new curriculum, a unit called AD1.2 is entitled "Emotion, your name is..." [34]. Its objective is to enable students to understand their emotions in different circumstances, more importantly, enable them 
to acknowledge the types of emotions that are more susceptible to drug abuse. Distinction of the effects of various personal emotions is the main feature of this unit. Naming or identifying the emotion is used as a way to enhance emotion competence.

\subsection{Understanding the Consequence of the Emotion-Driven Behavior}

The theories of normative ethics are generally grouped into two main types. The first is the deontological theories [35] suggesting that certain actions are right or wrong, or good or bad, without regard for their consequences. One such value system is the Rokeach's personal values [36]. Instrumental values, such as honesty or diligence, are examples of the deontological perspective. The rights of a human being or the pursuit of happiness are inviolable; therefore, the ends do not necessarily justify the means.

The other type of normative ethics theories is teleological [35]. The rightness of any action is determined by the goodness of its consequences. Sometimes we have to balance the means and the ends since the ends may not justify the means. An example is that despite every individual's right to the freedom of expression, resorting to out-of-control anger to vent frustration is not an appropriate action to take.

Adolescents should understand the consequences of emotion-driven behaviors. The consequences are not only individual-oriented; they can also influence other people closely related to the adolescents. For instance, an adolescent may feel sad about his/her academic performance despite painstaking efforts and may even feel helpless. This crisis in identity, combined with other life circumstances, such as family conflicts and peer relationship problems, may be something that an adolescent does not know how to cope with actively. Hence, an adolescent may resort to an avoidance strategy, such as taking drugs. However, drug dependence causes more pain to the adolescent and his/her family. The adolescent may get arrested for drug possession or irresponsible behavior triggered by drug dependence. From these examples, it is clear that the cost of drug dependence is enormous.

To regulate one's emotions, adolescents have to understand the possible negative behavioral consequences of their emotions to themselves and their families, schools, and peers. Only adolescents who are well aware of the effects of emotion-driven behavior know that they have to choose a better alternative in handling emotions. In addition, adolescents must be able to think of additional alternative emotion outlets or effective emotion handling strategies well before they experience that emotion. This is the principle of implementation intention $[37,38]$.

In the new curriculum, a unit called AD 1.3 is entitled "Emotional Survival Guide." Students are encouraged to think of the consequences of poorly managed emotions and work against those disruptive emotions. Moreover, they have to think of constructive behaviors so that they can act properly the next time they experience a particular emotion. They are required to make their own booklet of "Emotional Survival Guide." While they are making their booklet, they can rehearse appropriate behavior management. In this way, emotion-driven behavior consequences can be controlled more effectively.

\subsection{Use of an Inspirational Story with a Strong Message Against Substance Abuse to Trigger Emotion}

Kotter and Lorne [39] explored the most effective speeches made by great leaders and found that storytelling is the oft-used means to convey an inspirational message. Great speakers use short stories to engage their audience. In fact, stories are great tools to engage adolescents. Stories should not necessarily be intellectual nor fashionable but be able to strike an emotional chord in the hearts of the listeners. Only through such narratives can adolescents become more involved in lessons. If the message is more forceful, adolescents can regulate their emotion-driven thinking in class.

Where do the stories come from? If applicable, the instructor can prepare his/her own story, such as sharing how they have been on the edge of taking drugs or having committed other meaningless acts themselves. In fact, disclosure is an effective therapeutic tool for the class. In addition, the instructor can disclose his/her feelings, insights, strategy, support, challenge, and immediacy to the adolescents so that 
their emotional competence can be strengthened [40]. Moreover, the instructor can also collect up-to-date news about drug abuse for adolescents' discussion in order to catch their attention. The instructor can also inquire whether or not adolescents can cope with their emotions effectively so that they are drug-free. Indeed, storytelling is more effective than the one-way pedagogical method in promoting emotional competence to adolescents.

In the new curriculum, a unit called AD1.1 is entitled "Choose a Better Way" [34]. For instance, a story is told about a young chef who easily becomes irritated when he faces some unreasonable demands from a customer. Students are encouraged to choose endings that may occur when the chef chooses a particular way to deal with the problem. The endings are concerned with positive thinking, portraying the act of taking drugs as avoidance tactics, or constructive problem solving. The endings are designed according to the coping model by Lazarus and Folkman [21]. The story is based on a real life incident, in which a small event has triggered undesirable consequences. Students are encouraged to discuss how they can prevent themselves from acting recklessly and impulsively without considering the consequences of their actions.

\section{CONCLUSION}

In conclusion, the present paper argues that emotional competence is critical to adolescent development. It is an important building block for an effective antidrug education curriculum for junior secondary school students, through which adolescents can appreciate and regulate their emotions more properly. When we promote emotional competence among adolescents, we should understand its development among ado lescents. Three ways are suggested for the effective promotion of emotional competence: naming the emo tion, understanding the consequences of emotions and emotion-driven behavior, and using a story with a strong message against substance abuse to trigger emotions. These components are integrated in the newly developed curriculum of the Project P.A.T.H.S.

\section{ACKNOWLEDGMENT}

The preparation for this paper and Project P.A.T.H.S. were financially supported by the Hong Kong Jockey Club Charities Trust.

\section{REFERENCES}

[1] “Narcotics Division. Drug statistics," 2009, http://www.nd.gov.hk/en/crda_ess.htm .

[2] D. T. L. Shek, "Tackling adolescent substance abuse in Hong Kong: where we should and should not go," TheScientificWorldJOURNAL, vol. 7, pp. 2021-2030, 2007.

[3] U. Bronfenbrenner, The Ecology of Human Development, Harvard University Press, Cambridge, Mass, USA, 1979.

[4] HKSAR Government, "Policy Address 2007-08," 2008, http://www.policyaddress.gov.hk/07-08/eng/policy.html.

[5] HKSAR Government, "Policy Address 2008-09," 2008, http://www.policyaddress.gov.hk/08-09/eng/policy.html.

[6] D. T. L. Shek, "School drug testing: a critical review of the literature," TheScientificWorldJOURNAL, vol. 10, pp. 356-365, 2010.

[7] HKSAR Government, "Policy Address 2010-11,” 2010, http://www.policyaddress.gov.hk/10-11/index.html .

[8] Hong Kong Federation of Youth Groups, Anti-Drug Package, Author, Hong Kong, 2010.

[9] L. Meyer and H. Cahill, Principles for School Drug Education, Department of Education, Science and Training, Australia, 2004.

[10] D. W. Chan, "The hierarchy of strengths: their relationships with subjective well-being among Chinese teachers in Hong Kong," Teaching and Teacher Education, vol. 25, no. 6, pp. 867-875, 2009.

[11] Education Commission, Learning for Life, Learning Through Life: Reform Proposals for the Education System in Hong Kong, Education Blueprint for the 21st Century, Author, Hong Kong, 2000. 
[12] Narcotics Division, "Anti-drug information and resources," 2009, http://www.nd.gov.hk/tc/antidrug_resources .htm.

[13] Department of Health, “Adolescent Health Programme,” 2009, http://www.ahpshs.gov.hk/english/abo_us/abo_us .html.

[14] Education Bureau, "Enhanced Smart Teen Project," 2010, http://www.edb.gov.hk/index.aspx?nodeID= $926 \&$ langno $=1$.

[15] R. M. Lerner and L. Steinberg, "The scientific study of adolescent development," in Handbook of Adolescent Psychology, R. M. Lerner and L. Steinberg, Eds., John Wiley and Sons, Hoboken, NJ, USA, 2009.

[16] D. T. L. Shek, "Conceptual framework underlying the development of a positive youth development program in Hong Kong," in Positive Youth Development: Development of a Pioneering Program in a Chinese Society, D. T. L. Shek, H. K. Ma, and J. Merrick, Eds., Freund Publishing, London, UK, 2007.

[17] D. T. L. Shek, H. K. Ma, and R. C. F. Sun, "Development of a new curriculum in a positive youth development program," The Project P.A.T.H.S. in Hong Kong. In press.

[18] C. Izard, Human Emotions, Plenum Press, New York, NY, USA, 1977.

[19] M. Lewis, "Emotional competence and development," in Improving Competence Across the Lifespan: Building Interventions Based on Theory and Research, D. Pushkar, M. W. Bukowski, A. E. Schwartzman, D. M. Stack, and D. R. White, Eds., Plenum Press, New York, NY, USA, 1998.

[20] R. Lazarus and R. Launier, "Stress-related transactions between person and environment," in Perspective in International Psychology, A. Pervin and M. Lewis, Eds., Plenum Press, New York, NY, USA, 1978.

[21] R. Lazarus and S. Folkman, Stress, Appraisal, and Coping, Springer, New York, NY, USA, 1984.

[22] J. D. Mayer and P. Salovey, "What is emotional intelligence?" in Emotional Development and Emotional Intelligence: Educational Implications, P. Salovey and D. Sluyter, Eds., Basic Books, New York, NY, USA, 1997.

[23] N. Eisenberg, "The socialization of socioemotional competence," in Improving Competence Across the Lifespan: Building Interventions Based on Theory and Research, D. Pushkar, M. W. Bukowski, A. E. Schwartzman, D. M. Stack, and D. R. White, Eds., Plenum Press, New York, NY, USA, 1998.

[24] R. W. Robins, O. P. John, A. Caspi, T. E. Moffitt, and M. Stouthamer-Loeber, "Resilience, overcontrolled, and undercontrolled boys: three replicable personality types," Journal of Personality and Social Psychology, vol. 70, no. 1, pp. 157-171, 1996.

[25] B. E. Compas and A. Harding, "Competence across the lifespan: lessons from coping with cancer," in Improving Competence Across the Lifespan: Building Interventions Based on Theory and Research, D. Pushkar, M. W. Bukowski, A. E. Schwartzman, D. M. Stack, and D. R. White, Eds., Plenum Press, New York, NY, USA, 1998.

[26] A. L. Freitas and G. Downey, "Resilience: a dynamic perspective," International Journal of Behavioral Development, vol. 22, no. 2, pp. 263-285, 1998.

[27] S. S. Tomkins, Affect, Imagery, and Consciousness, Springer, New York, YN, USA, 1963.

[28] S. Harter, "Developmental changes in self-understanding across the 5 to 7 shift," in Reason and Responsibility: The Passage Through Childhood, A. Sameroff and M. Haith, Eds., University of Chicago Press, Chicago, Ill, USA, 1996.

[29] D. Baumrind, "Parenting styles and adolescent development," in The Encyclopedia of Adolescence, J. BrooksGunn, R. Lerner, and A. C. Peterson, Eds., Garland, New York, NY, USA, 1991.

[30] D. Elkind, Teenagers in Crisis: All Grown Up and No Place to Go, Perseus Books, City, State, USA, 1998.

[31] C. Giligan, "Adolescent development reconsidered," in Adolescent Social Beahvior and Health, E. E. Irwin, Ed., Jossey-Bass, San Francisco, Calif, USA, 1987.

[32] R. S. Siegler, "Beyond competence—-toward development," Cognitive Development, vol. 12, no. 3, pp. 323-332, 1997.

[33] J. Lehrer, How We Decide, Mariner Books, Boston, Mass, USA, 2009.

[34] P.A.T.H.S. to Adulthood, "Tier 1 New," 2010, http://www.paths.hk/download/tier1_new.asp .

[35] F. G. Reamer, Social Work Values and Ethics, Columbia University, New York, NY, USA, 2006.

[36] M. Rokeach, The Nature of Human Values, The Free Press, New York, NY, USA, 1973.

[37] I. Ajzen, "Perceived behavioral control, self-efficacy, locus of control, and the theory of planned behavior," Journal of Applied Social Psychology, vol. 32, no. 4, pp. 665-683, 2002.

[38] E. J. Parks-Stamm, P. M. Gollwitzer, and G. Oettingen, "Action control by implementation intentions: effective cue detection and efficient response initiation," Social Cognition, vol. 25, no. 2, pp. 248-266, 2007. 
[39] J. P. Kotter and A. W. Lorne, Buy-In: Saving Your Good Idea from Getting Shot Down, Harvard Business Press, Cambridge, Mass, USA, 2010.

[40] S. Knox and C. E. Hill, "Therapist self-disclosure: research-based suggestions for practitioners," Journal of Clinical Psychology, vol. 59, no. 5, pp. 529-539, 2003.

\section{This article should be cited as follows:}

Ben M. F. Law and Tak Yan Lee, "Importance of Emotional Competence in Designing an Antidrug Education Curriculum for Junior Secondary School Students in Hong Kong," TheScientificWorldJOURNAL, vol. 11, pp. 2257-2265, 2011. 